\title{
INTEGRACIÓN DE LAS NORMAS INTERNACIONALES DE DERECHOS HUMANOS EN LOS ORDENAMIENTOS ESTATALES DE LOS PAÍSES DE IBEROAMÉRICA
}

\section{Loretta ORTIZ AHLF*}

RESUMEN: El artículo analiza, desde la perspectiva del derecho internacional e interno, tres temas: el sistema de incorporación, la recepción y jerarquía de las normas de derechos humanos internacionales en los sistemas jurídicos de Iberoamérica. Se observa cómo en el caso de los tratados internacionales en materia de derechos humanos su proceso de incorporación está sujeto en la mayoría de los casos al cumplimiento de requisitos determinados por las Constituciones de Iberoamérica, con lo cual se adopta un sistema dualista; en cambio si nos referimos a las normas consuetudinarias, éstas se incorporan a través de un proceso de remisión de la norma constitucional a la internacional de manera automática. En lo relativo a la jerarquía de los tratados en materia de derechos humanos, distinguimos los rangos supraconstitucional, constitucional, legal y supralegal; la mayoría de los países de Iberoamérica les conceden el rango de constitucional y supralegal.

ABSTRACT: The article analyses three subjects from the standpoint of international and municipal law: the system of incorporation, reception and hierarchy of international $\mathrm{Hu}$ man Rights norms in Spanish-American legal systems. It is observed that in the case of international human rights treaties, their incorporation is subject to a set of requirements established in Spanish-American constitutions, whereby a dualist system is adopted. However, customary norms are incorporated automatically through a process of reference from the constitutional to the international norm. Regarding the hierarchy of international human rights treaties, the supra-constitutional, constitutional, legal, and supra-legal ranks are distinguished, and most Spanish-American countries grant them constitutional or supra-legal rank.

RÉSUMÉ: Cet article analyse d'un point de vue international et national, le système d'incorporation, de réception et de hiérarchisation des normes relatives aux droits de l'homme dans les systèmes juridiques hispano-américains. L'auteur examine le processus d'incorporation des traités internationaux en matière de droits de l'homme et vérifie que ce processus est assujetti, dans la plupart des cas, à un certain nombre de formalités déterminées par les Constitutions nationales, formant un système de type dualiste. En ce qui concerne les normes coutumières, ce processus d'incorporation se fait par le biais d'un agencement automatique de la norme constitutionnelle vers la norme internationale. Dans l'hiérarchie des traités en matière de droits de l'homme, on distingue différents niveaux: un niveau supraconstitutionnel, un niveau constitutionnel, un niveau légal et un niveau supralégal. La plupart des pays hispano-américains concèdent à ces nouvelles normes un niveau constitutionnel et supralégal.

* Directora del Departamento de Derecho de la Universidad Iberoamericana y profesora de derecho internacional. 
SuMARIO: I. Introducción. II. Procedimiento de vinculación entre los ordenamientos internos y el derecho internacional. III. Recepción de las normas internacionales. IV. Jerarquía de las normas internacionales.

\section{INTRODUCCIÓN}

El tema de la integración de las normas internacionales de los derechos humanos a los derechos internos de los Estados de Iberoamérica, permite un análisis en tres vertientes, una en razón de los procedimientos de vinculación, la segunda que atiende a la forma de recepción de dichas normas y una tercera relativa a la jerarquía.

Las relaciones del derecho internacional con el interno se encuentran sometidas a una fuerte revisión, lo cual en forma similar se refleja en el derecho constitucional, especialmente por las tendencias actuales de reducir la soberanía estatal a sus justos límites. Además, frente al fenómeno de la evolución constante del derecho internacional, se observa la necesidad de adaptar el derecho interno a las nuevas exigencias que plantean las organizaciones internacionales en materias tales como los derechos humanos.

Hoy ya no cabe sostener, como antaño, que el problema de las relaciones entre el derecho interno y el internacional sea esencialmente teórico. Por una parte, los textos constitucionales han ido abriendose a la enumeración, definición y amparo de los derechos y libertades individuales y colectivos, subrayando su carácter normativo y la aplicabilidad directa de los preceptos.

¿Cuáles son las respuestas que el derecho interno ha dado a problemas tan novedosos?, en algunos casos, la falta de regulación o lagunas en las Constituciones antiguas ha provocado una reforma constitucional, una nueva Constitución o un ajuste vía precedentes judiciales. ${ }^{1}$

Otra respuesta ha sido el reconocimiento de la existencia de mutaciones jurídicas. Las normas formalmente son las mismas, los repartos de competencia no han sido alterados, pero el derecho material del Estado sí ha sufrido un cambio.

1 Vanossi, Jorge Reinaldo A., "El derecho internacional en el derecho constitucional comparado de América", varios autores, XV Curso de Derecho Internacional-Comité Jurídico Interamericano, Washington, D. C., OEA, 1986, pp. 85 y ss. 
La tercera clase de respuesta, parte del reconocimiento de la falta de posibilidad de control sobre la base de la aplicación de nuevas soluciones jurídicas ante el caso de que éstas fueran confrontadas y pudieran impugnarse por ser contradictorias o incompatibles con el orden jurídico. La forma de solucionar el conflicto consiste en eliminar el control; por ejemplo, si el control es de tipo judicial, como ocurre en muchos países de América, donde incluso los tratados y demás normas emanadas del derecho externo están sujetas a control constitucional por la vía de órganos judiciales internos, hay que acudir a la famosa categoría de "cuestiones políticas" con lo cual quedan exentas de todo tipo de control judicial o jurídico.

Las Constituciones de Iberoamérica pueden clasificarse en cuatro grupos, el primero, del silencio, donde ubicamos a las Constituciones más antiguas, que tienen mayores dificultades de rearticulación interna para reordenar las pirámides jurídicas, como en el caso de México.

Un segundo grupo integrado por las Constituciones de los países centroamericanos, los cuales por haber conformado un Estado centroamericano, permanece en sus Constituciones una temática integracionista muy marcada.

En el tercer grupo ubicamos a las Constituciones de aquellos países que han adoptado la decisión política fundamental a favor de los procesos de integración, pero que no han articulado los mecanismos ni han redistribuido las competencias desde el punto de vista normativo, y recurren a cláusulas programáticas, no directamente operativas, como es el caso de la Constitución del Ecuador.

Por último, estarían aquellas Constituciones donde no sólo se han tomado las decisiones políticas fundamentales, sino que además se han articulado los mecanismos y procedimientos tendentes a la solución de problemas concretos, contemplando un nuevo rango para los tratados en materia de derechos humanos; ubicamos dentro de este grupo, entre otras, las de Argentina, Colombia, España, Portugal, Honduras y Guatemala.

\section{PROCEDIMIENTO DE VINCULACIÓN ENTRE LOS ORDENAMIENTOS INTERNOS Y EL DERECHO INTERNACIONAL}

Independientemente de que se adopte el dualismo o monismo, resulta necesario que el derecho interno incorpore al derecho internacional, a través de un mandato constitucional que determina qué normas se integran al ordenamiento nacional. 
Un análisis de las Constituciones de Iberoamérica nos demuestra que básicamente los procedimientos de vinculación se reducen a dos sistemas: el de remisión de la norma interna a la internacional y el de incorporación de las normas internacionales al derecho interno, después de cumplir determinados requisitos.

a) Procedimiento de incorporación. Este procedimiento de vinculación lo siguen todos los países de Iberoamérica en lo atinente a la materia de los tratados, sujetan la aplicación, en el ámbito interno, al cumplimiento de distintos requisitos que varían de un Estado a otro, dichos requisitos pueden consistir por ejemplo: en una declaración previa de constitucionalidad, en su conformidad con la Constitución, en una aprobación simple o calificada dependiendo de la materia por un órgano parlamentario, la celebración del tratado por el Poder Ejecutivo o presidente o por una combinación de los mismos.

b) Procedimiento de remisión. Algunas de las Constituciones utilizan como mecanismos de vinculación la remisión a las normas internacionales, dicha técnica es utilizada en materias como fronteras marítimas, espacio aéreo y la incorporación de los principios de derecho internacional.

Cabe señalar que no se sujeta la incorporación de las normas internacionales, en las materias antes señaladas, al cumplimiento de determinados requisitos, como el de la conformidad con el derecho interno o ajustarse al marco constitucional, podría afirmarse incluso que en la mayoría de los casos las normas de derecho internacional tienen el mismo rango jerárquico que las constitucionales, por cuanto se lleva a acabo una remisión en blanco.

En ambos casos, con la remisión a principios de derecho internacional o normas de derecho internacional se incorporan normas consuetudinarias o de ius cogens, las convencionales están sujetas a distintos requisitos como se ha señalado, de manera muy clara se expresa dicha distinción en el caso de la Constitución de Portugal, al puntualizar:

Artículo 8. Derecho internacional:

1. Las normas y los principios de derecho internacional general o común pasan a formar parte integrante del derecho portugués.

2. Las normas contenidas en convenciones internacionales ratificadas y aprobadas entrarán en vigor una vez publicadas oficialmente y en cuanto vinculen internacionalmente al Estado portugués. 
3. Las normas emanadas de órganos competentes de organizaciones internacionales de las cuales Portugal sea parte entrarán en vigor directamente en el orden interno, de conformidad con lo establecido en los respectivos tratados constitutivos.

En materia de derechos humanos, se adoptan ambos procedimientos de vinculación para la incorporación de los tratados, deben ajustarse dichos instrumentos a diversos requerimientos establecidos tanto en sus Constituciones como en su legislación. En cambio, las normas consuetudinarias en materia de derechos humanos, contenidas en diversas declaraciones, se incorporan mediante mandato constitucional por una remisión de la norma constitucional a la norma internacional de derechos humanos.

\section{RECEPCIÓN DE LAS NORMAS INTERNACIONALES}

Una vez incorporadas las normas internacionales al derecho interno, después de haber cumplido los requisitos necesarios para ello, la cuestión que debe resolverse es la aplicación de las normas internacionales en el ámbito interno, en el caso de las normas auto-aplicativas, éstas formarán parte del derecho interno sin requerir de acto de implementación legislativo.

En cambio, las no auto-aplicativas, si se siguió un sistema de transformación de la norma internacional en ley o se incorporó sin modificar su naturaleza, requerirán en el primer caso, de transformar el tratado en ley y emitirla en el mismo acto o en un momento posterior de la legislación necesaria para su aplicación; en el caso de incorporarse sin modificar su naturaleza, se requiere de emitir las leyes y demás disposiciones necesarias para su aplicación o incluso reformar aquella legislación que sea contraria al tratado que se incorpora.

La mayoría de los Estados de Iberoamérica sigue el sistema de que una vez que el tratado se incorpora por reunir los requisitos constitucionales, son publicados en las gacetas o diarios oficiales. En estos casos, las normas convencionales autoplicativas no requieren para su aplicación de ningún acto de carácter administrativo o legislativo posterior, en cambio las normas no-autoplicativas requieren en algunas ocasiones de un acto legislativo o administrativo, mediante el cual el Estado en cuestión instrumenta la aplicación interna. ${ }^{2}$

2 Véase Remiro Brotóns, Antonio et al., Derecho internacional público, Ed. McGraw-Hill, 1997, pp. 356 y ss. 
La función de instrumentar la aplicación interna se dificulta en algunos de los gobiernos federales en los casos de los tratados que versen en materia local, caso en el cual pueden quedar involucradas en la implementación de los tratados las autoridades locales. ${ }^{3}$

Cabe aclarar que la mayoría sigue el sistema de recepción, incorporando al tratado sin modificar su naturaleza jurídica; hay algunas excepciones, como los casos de España y Venezuela.

El artículo 93 de la Constitución de España dispone:

Mediante ley orgánica se podrá autorizar la celebración de tratados por los que se atribuya a una organización o institución internacional el ejercicio de competencias derivadas de la Constitución. Corresponde a las Cortes Generales o al Gobierno, según los casos, la garantía del cumplimiento de estos tratados y de las resoluciones emandas de los organismos internacionales o supranacionales titulares de la cesión. ${ }^{4}$

Por su parte, el artículo 128 de la Constitución de Venezuela señala:

Los tratados o convenios internacionales que celebre el Ejecutivo Nacional deberán ser aprobados mediante ley especial para que tengan validez, salvo que mediante ellos se trate de ejecutar o perfeccionar obligaciones preexistentes de la República, de aplicar principios expresamente reconocidos por ella, de ejecutar actos ordinarios en las relaciones internacionales o de ejercer facultades que la ley atribuya expresamente al Ejecutivo Nacional. Sin embargo, la Comisión Delegada del Congreso podrá autorizar la ejecución provisional de tratados o convenios internacionales cuya urgencia así lo requiera, los cuales serán sometidos, en todo caso, a la posterior aprobación o improbación del Congreso. En todo caso, el Ejecutivo Nacional dará cuenta al Congreso en sus próximas sesiones, de todos los acuerdos jurídicos internacionales que celebre, con indicación precisa de su carácter y contenido, estén o no sujetos a su aprobación. ${ }^{5}$

Las ventajas que presenta el sistema de transformación del tratado en ley, se fincan en que las dificultades que se presentan en su aplicación

3 Véase Barker, Robert S., "Cuestiones procesales suscitadas en el sistema federal de Estados Unidos de América", Revista Interamericana de Abogados, Talleres Gráficos de First Publishing, junio de 2000, pp. 161 y ss.

4 Constitución Española del 6 de diciembre de 1978, reformada el 27 de agosto de 1992; López Guerra, Luis y Aguiar, Luis, Las Constituciones de Iberoamérica, Madrid, Ilustre Colegio de Abogados, 1998, pp. 504 y 518.

5 Idem, e ibidem, p. 1104, respectivamente. 
interna se reducen, sin embargo se corre el riego que al perder su identidad internacional, los jueces utilicen como criterios de interpretación los establecidos en el derecho interno y no los marcados por el derecho internacional, que resultan obligatorios en razón de las normas convencionales o consuetudinarias sobre la materia para los países de Iberoamérica.

Las dificultades que representa, en las Constituciones del silencio, la aplicación de los tratados, radica en que los constituyentes de esas épocas jamás pensaron que por vía de los tratados se legislaba para toda la nación en las más diversas materias, y en algunas ocasiones con un efecto inmediato sobre los individuos; dichas dificultades se resuelven, en algunas de las Constituciones del cuarto grupo o contemporáneas, incluyendo un capítulo específico en materia de tratados en la Constitución que aluda entre otras cuestiones a la entrada en vigor, denuncia, normas de interpretación aplicables y jerarquía. En ese sentido ubicamos en la Constitución de España, su capítulo tercero, "De los tratados internacionales".

Una cuestión olvidada por las Constituciones del silencio es la entrada en vigor de los tratados internamente, la derogación, modificación o suspensión de las mismas, con lo cual podía llegarse al absurdo de sostener que el tratado entra en vigor, una vez publicado internamente, aunque internacionalmente no haya entrado en vigor.

Para resolver esta clase de problemas en la aplicación de los tratados internamente, el artículo 96 de la Constitución de España señala:

1. Los tratados internacionales válidamente celebrados, una vez publicados oficialmente en España, formarán parte del ordenamiento interno. Sus disposiciones sólo podrán ser derogadas, modificadas o suspendidas en la forma prevista en los propios tratados o de acuerdo con las normas generales del derecho internacional.

2. Para la denuncia de los tratados y convenios internacionales se utilizará el mismo procedimiento previsto para su aprobación en el artículo 94.

En relación con la aplicación directa de los derechos y libertades en el sistema español, debe considerarse lo señalado en el artículo 53 de la Constitución de España:

1. Los derechos y libertades reconocidos en el Capítulo segundo del presente Título vinculan a todos los poderes públicos. Sólo por ley, que en todo caso deberá respetar su contenido esencial, podrá regularse el ejerci- 
cio de tales derechos y libertades, que se tutelarán de acuerdo con lo previsto en el artículo 161. 1.a).

2. Cualquier ciudadano podrá recabar la tutela de las libertades y derechos reconocidos en el artículo 14 y la Sección Primera del Capítulo Segundo ante Tribunales ordinarios por un procedimiento basado en los principios de preferencia y sumariedad y, en su caso, a través del recurso de amparo ante el Tribunal Constitucional. Este último recurso será aplicable a la objeción de conciencia reconocida en el artículo 30.

3 . El reconocimiento, el respeto y la protección de los principios reconocidos en el Capítulo Tercero informarán la legislación positiva, la práctica judicial y la actuación de los poderes públicos. Sólo podrán ser alegados ante la jurisdicción ordinaria de acuerdo con lo que dispongan las leyes que las desarrollen. ${ }^{6}$

De la redacción de dicho artículo no puede deducirse que necesariamente los derechos y libertades del capítulo segundo del título primero, requieran para tener aplicabilidad directa de un desarrollo legislativo, debe interpretarse la disposición constitucional, en el sentido de que si se regulan, requieren de una ley orgánica.

En todo caso, se señala en la doctrina que las libertades y derechos establecidos en el capítulo segundo del título primero, son autoaplicativos o de aplicación directa, en razón de que el mismo Tribunal Supremo en sentencias de 3 de julio, 27 de octubre, 5 de noviembre y 17 de diciembre de 1979, así lo ha resuelto.

Cabe señalar que carecen de eficacia directa, los derechos de la tercera sección, del artículo 53, ya que, no gozan del beneficio de la protección a través del recurso de amparo ordinario y constitucional, y por tanto no pueden beneficiarse de los procedimientos y tribunales ordinarios. ${ }^{7}$

Si tiene importancia la operatividad de las normas internacionales en el ámbito interno, el tema resulta capital si se vincula con los derechos humanos. De tal suerte, que la Corte Interamericana de Derechos Humanos, en la "Opinión consultiva sobre la exigibilidad del derecho de rectificación o respuesta en caso de inexistencia de una ley nacional al respecto de un Estado parte en la convención", ha expresado, en parte, que:

6 Linde, Enrique et al., El sistema europeo de protección de los derechos humanos, Madrid, Civitas, 1983, p. 163.

7 Idem. 
La tesis de que la frase en las condiciones que establezca la ley utilizada en el artículo 14.1 (de la Convención) solamente facultaría a los Estados Partes a crear por ley el derecho de rectificación o respuesta, sin obligarlos a garantizarlo mientras su ordenamiento interno no lo regule, no se compadece ni con el sentido corriente de los términos empleados, ni con el contexto de la Convención. ${ }^{8}$

En relación con el tratamiento que se ha dado al tema en los Estados que han ratificado los instrumentos interamericanos sobre derechos humanos, un buen ejemplo se observa en la sentencia dictada en el caso Microomnibus Barracas de Belgrano S. A. en que la Suprema Corte de Argentina sostuvo: “...3o. Que, del examen de la jurisprudencia de la Corte, surge que el otorgamiento del carácter operativo o programático a los tratados internacionales ha dependido de si su ejercicio había sido supeditado o no a la adopción, en el caso concreto, de medidas legislativas por parte del orden jurídico interno del país contratante". 9

La Suprema Corte argentina en este caso admitió la operatividad de al menos algunas disposiciones del Pacto de San José, al interpretar que el texto del artículo 8o., inciso 1o., de la Convención Americana, al igual que los artículos 7o., inciso 5o., y 8o., inciso 2o., letra h, de la citada convención, no requieren una reglamentación posterior.

Jiménez de Aréchega menciona dos condiciones para que una norma sea autoejecutiva:

Primero, debe ser una norma de la cual sea posible derivar en forma directa un derecho o una pretensión a favor de un individuo que tenga interés legítimo en la aplicación de la regla en su caso, y que comparece ante el juez o el administrador solicitando esa aplicación; en segundo lugar, la regla debe ser lo suficientemente específica como para poder ser aplicada judicialmente, sin que su ejecución esté subordinada a un acto legislativo o a medidas administrativas subsiguientes. ${ }^{10}$

8 Opinión Consultiva OC-7/86, 26 de agosto de 1986, Exigibilidad del Derecho de Rectificación o Respuesta (artículos 14.1; 1.1 y 2), Convención Americana sobre Derechos Humanos, pp. 12 y 13.

9 Acevedo, Domingo E., "Relación entre el derecho internacional y el derecho interno", Seminario Regional sobre las Medidas Nacionales de Aplicación de Derecho Internacional Humanitario, San José Costa Rica, 18-21 de junio de 1991, p. 26.

10 Ortiz Ahlf, Loretta, Derecho internacional público, 2a. ed., Oxford Press, 1993, p. 40. 
Continúa señalando que existe una presunción a favor del carácter ejecutable de una disposición convencional, pues se ha considerado que la disposición de un tratado es ejecutable por sí misma, "a menos que contenga estipulación expresa de ejecución por medio de una ley o pertenezca a esa categoría excepcional de tratados a los que no se puede, por su propia naturaleza, dar efecto como derecho ex propio vigore". Señala como ejemplos de normas ejecutivas por su propia naturaleza la cláusula de la nación más favorecida y las relativas a derechos humanos.

En lo atinente a la costumbre internacional, varias de las Constituciones de Iberoamérica incorporan por una remisión de la misma las normas consuetudinarias en materia de derechos humanos. En estos casos no se requiere de actos de implementación de carácter legislativo, ya que la norma internacional se aplica directamente en el ámbito interno de manera operativa.

Cabe recordar que el contenido de la norma está determinado en el ámbito internacional y que el derecho interno lo recoge directamente; como ejemplo de esta clase de normas ubicamos la siguiente:

La Constitución de Brasil en su artículo cuarto puntualiza:

La República Federativa de Brasil rige sus relaciones internacionales por los siguientes principios:

I. Independencia nacional.

II. Primacía de los derechos humanos.

III. Autodeterminación de los pueblos.

IV. No intervención.

V. Igualdad entre los Estados.

VI. Defensa de la paz.

VII. Solución pacífica de los conflictos.

VIII. Repudio al terrorismo y al racismo.

IX. Cooperación entre los pueblos para el progreso de la humanidad.

X. Concesión de asilo político. ${ }^{11}$

En varias Constituciones de Iberoamérica se incorpora la costumbre internacional en materia de derechos humanos, independientemente del sistema de incorporación de los tratados, otorgando a la costumbre internacional incorporada el rango constitucional. 
Un ejemplo claro lo constituye la Constitución de Portugal, que establece en su artículo 16.2.: "Los preceptos constitucionales y legales relativos a los derechos fundamentales deben ser interpretados e integrados en armonía con la Declaración Universal de los Derechos del Hombre". ${ }^{12}$

De igual forma, la Constitución Española en su artículo 10 dispone: "Las normas relativas a los derechos fundamentales y a las libertades que la Constitución reconoce, se interpretarán de conformidad con la Declaración Universal de Derechos Humanos y los tratados y acuerdos internacionales sobre las mismas materias ratificadas por España".

\section{JERARQUÍA DE LAS NORMAS INTERNACIONALES}

La eficacia y efectividad del derecho internacional en el ámbito interno, no sólo depende de las formas de recepción de las mismas, también del rango jerárquico que se les otorga en las Constituciones, en ellas se observa un tratamiento diverso para los tratados de las normas consuetudinarias que se aplican directamente por remisión de la norma constitucional.

\section{Jerarquía de los tratados}

En términos generales, las Constituciones de Iberoamérica otorgan a los tratados en materias de derechos humanos cuatro tipos de rango: supranacional, constitucional, supra-legal y legal.

En Iberoamérica, como ejemplos de Constituciones que ubican con un rango supranacional a los tratados de derechos humanos, ubicamos a Guatemala, Honduras y Colombia.

La Constitución de Guatemala, con relación a los instrumentos internacionales, establece en su artículo 46 el principio de que sólo en materia de derechos humanos los tratados y convenciones tienen preeminencia sobre el derecho interno, dispone: "Preeminencia del Derecho Internacional. Se establece el principio general de que en materia de derechos humanos, los tratados y convenciones aceptados y ratificados por Guatemala, tienen preeminencia sobre el derecho interno". ${ }^{13}$

12 La Constitución de la República Portuguesa de 1976, revisada cuatro veces (1982, 1989, 1992, 1997); López Guerra y Aguiar, op. cit., nota 4, p. 918.

13 Constitución Política de la República de Guatemala del 31 de mayo de 1985, reformada el 17 de noviembre de 1993; López Guerra y Aguiar, op. cit., nota 4, p. 547. 
Está formula genérica de preeminencia de los instrumentos internacionales acerca de derechos humanos sobre el derecho interno, podría dar lugar a dudas, sobre si dicha supremacía se presenta incluso en el caso de la Constitución. Sin embargo, dicha duda puede aclararse al conocerse, como señala Carlos Ayala, el origen de la disposición, ya que dicho origen estuvo vinculado con la opinión consultiva de la Corte Interamericana de Derechos Humanos OC-383 del 8 de septiembre de 1983, en la cual la corte estableció, que un país no puede, aunque su Constitución se lo permita (como era el caso de Guatemala), "aplicar la pena de muerte a delitos para los cuales no estaba contemplada anteriormente en su legislación interna". ${ }^{14}$

De manera similar señala el artículo 93 de la Constitución de Colombia: "Los tratados y convenios internacionales ratificados por el Congreso, que reconocen los derechos humanos y que prohíben su limitación en los estados de excepción, prevalecen en el orden interno. Los derechos y deberes consagrados en esta Carta, se interpretarán de conformidad con los tratados internacionales sobre derechos humanos ratificados por Colombia". ${ }^{15}$

En el caso de Honduras, el artículo 16 establece que los tratados celebrados con otros Estados forman parte del derecho interno; y el 18, consagra la preeminencia de los tratados sobre las leyes, en caso de conflicto. Pero además, la propia Constitución en su artículo 17 contempla: "Cuando un tratado internacional afecte una disposición constitucional, debe ser aprobado por el mismo procedimiento que rige la reforma de la Constitución antes de ser ratificado por el Poder Ejecutivo". ${ }^{16}$

En este caso opera una reforma de la Constitución por la vía de un tratado internacional, que adquiere el carácter de ley constitucional capaz de modificar el texto de la carta magna, en virtud de una autorización expresa o delegación del poder constituyente, ya que, de lo contrario en caso de no efectuarse la aprobación del tratado por el procedimiento de reforma constitucional, el mismo resultaría inconstitucional.

14 Ayala Corao, Carlos M., La jerarquía de los tratados de derechos humanos (en prensa).

15 Constitución Política de Colombia del 7 de julio de 1991, reformada en seis ocasiones; López Guerra y Aguiar, op. cit., nota 4, p. 201.

16 Constitución de la República de Honduras del 20 de enero de 1982; López Guerra y Aguiar, op. cit., nota 4, p. 601. 
Dentro de las Constituciones que conceden a los tratados el mismo rango de Constitución, ubicamos a la Constitución de Argentina, la cual en su artículo 75 , fracción 22 , señala:

\section{Corresponde al Congreso:}

...22. Aprobar o desechar tratados concluidos con las demás naciones y con las organizaciones internacionales y los concordatos con la Santa Sede. Los tratados y concordatos tienen jerarquía superior a las leyes.

La Declaración Americana de los Derechos y Deberes del Hombre; la Declaración Universal de los Derechos Humanos; la Convención Americana de Derechos Humanos; el Pacto Internacional de Derechos Económicos, Sociales y Culturales; el Pacto Internacional de Derechos Civiles y Políticos y su Protocolo Facultativo; la Convención sobre la Prevención y la Sanción del Delito de Genocidio, la Convención Internacional sobre la Eliminación de todas las Formas de Discriminación Racial; la Convención sobre la Eliminación de todas las Formas de Discriminación contra la Mujer; la Convención contra la Tortura y otros Tratos o Penas Crueles, Inhumanos o Degradantes; la Convención sobre los Derechos del Niño; en las condiciones de su vigencia, tienen jerarquía constitucional, no derogan artículo alguno de la primera parte de esta Constitución y deben entenderse complementarias de los derechos y garantías por ella reconocidos. Sólo podrán ser denunciados en su caso, por el Poder Ejecutivo Nacional, previa aprobación de las dos terceras partes de la totalidad de los miembros de cada cámara. ${ }^{17}$

Otras Constituciones de Iberoamérica le otorgan un rango supralegal a todos tratados vinculados con la materia de derechos humanos; en este caso, los tratados prevalecen sobre las leyes nacionales, este sistema lo siguen: Costa Rica, El Salvador, Paraguay y Ecuador.

La Constitución de Costa Rica, en su artículo 7o., señala: "Los tratados públicos, los convenios internacionales y los concordatos, debidamente aprobados por la Asamblea legislativas, tendrán desde su promulgación o desde el día que ellos designen, autoridad superior a las leyes". ${ }^{18}$

Por su parte, la Constitución de El Salvador en su artículo 144 dispone: “...La ley no podrá modificar o derogar lo acordado en un tratado vi-

17 Constitución de la Nación de Argentina del 10 enero de 1995; López Guerra y Aguiar, op. cit., nota 4, p. 30.

18 Constitución Política de la República de Costa Rica del 7 de noviembre de 1949 ha sufrido numerosas reformas; López Guerra y Aguiar, op. cit., nota 4, p. 276. 
gente para El Salvador. En caso de conflicto entre el tratado y la ley, prevalecerá el tratado". ${ }^{19}$

Paraguay establece el principio de supremacía constitucional y el de prioridad del tratado sobre las leyes en su artículo 137 que dispone: "La ley suprema de la República es la Constitución. Ésta, los tratados, convenios y acuerdos internacionales aprobados y ratificados, las leyes dictadas por el congreso y otras disposiciones jurídicas de inferior jerarquía, sancionadas en consecuencia, integran el derecho positivo nacional en el orden de prelación enunciado". ${ }^{20}$

La Constitución de Ecuador en sus artículos 163 y 274 otorga primacía a los tratados sobre las leyes; el artículo 163 dispone:

Las normas contenidas en los tratados y convenios internacionales, una vez promulgados en el Registro Oficial, formarán parte del ordenamiento jurídico de la República y prevalecerán sobre leyes y otras normas de menor jerarquía. $^{21}$

En el caso de España también puede inferirse que los tratados internacionales en materia de derechos humanos tienen una jerarquía supralegal, si se atiende a los antecedentes del artículo 96 y a la interpretación de dicha disposición por el Tribunal Supremo y el Consejo de Estado. ${ }^{22}$

Los tratados internacionales válidamente celebrados forman parte del derecho español, únicamente pueden ser derogados, modificados o suspendidos de acuerdo con las disposiciones del propio tratado en cuestión, lo cual resulta acorde con las Convenciones de Viena sobre el Derecho de los Tratados de 1969 y de 1986. Sin embargo, no puede inferirse que por ese motivo tienen una jerarquía superior los tratados, ya que las normas internas provienen de fuentes diversas a las normas internacionales.

En todo caso, la jerarquía superior puede inferirse de una interpretación sistemática del articulado relativo a los tratados en la Constitución española, la jurisprudencia del Tribunal Supremo y el Consejo de Estado.

19 Constitución de la República de El Salvador de 1983, reformada en 1992, 1994 y 1996; López Guerra y Aguiar, op. cit., nota 4, p. 477.

20 Constitución de la República de Paraguay del 20 de junio de 1992; López Guerra y Aguiar, op. cit., nota 4, p. 834.

21 Constitución Política de la República de Ecuador del 30 de abril de 1998; López Guerra y Aguiar, op. cit., nota 4, p. 425.

22 Linde, Enrique et al., op. cit., nota 6, pp. 173 y ss. 
En un cuarto grupo ubicamos a las Constituciones que otorgan el mismo rango jerárquico a los tratados y a las leyes, en algunos casos únicamente en lo relativo a las leyes federales.

La Constitución de México dispone en su artículo 133:

Esta Constitución, las leyes del Congreso de la Unión que emanen de ella y todos los tratados que estén de acuerdo con la misma, celebrados y que se celebren por el Presidente de la República, con la aprobación del Senado, serán Ley Suprema de toda la Unión. Los jueces de cada Estado se arreglarán a dicha Constitución, leyes y tratados, a pesar de las disposiciones en contrario que pueda haber en las Constituciones o leyes de los Estados. ${ }^{23}$

Esta disposición constituye un claro ejemplo de las Constituciones del silencio, por cuanto no establece en caso de contradicción entre una ley federal y un tratado cuál norma debe prevalecer, ante esta laguna la Suprema Corte de México hasta 1999, se pronunció puntualizando en una tesis aislada, que prima el tratado sobre las leyes federales o locales. ${ }^{24}$

En el caso de la Constitución de Venezuela, exige en su artículo 124 que, salvo los supuestos allí establecidos, los tratados y convenios internacionales que celebre el Ejecutivo nacional, "deberán ser aprobados mediante ley especial para que tengan validez". Por lo cual, si bien dicha Constitución no establece expresamente el rango de los tratados en el orden interno, al incorporarse éstos mediante ley, pasan a tener el mismo rango de la ley interna.

Finalmente, los Estados de la comunidad internacional que no parten de los tratados en materia de derechos humanos, pueden resultar obligados en razón de una norma consuetudinaria, norma que puede tener incluso el rango de norma de ius cogens, razón por la cual, es indispensable contar en las Constituciones modernas, con una disposición relativa a la incorporación de las normas en materia de derechos humanos consuetudinarias y su jerarquía supra-legal, con el fin de asegurar el cumplimiento de dichas normas, so pena de incurrir en responsabilidad internacional.

23 Constitución Política de los Estados Unidos Mexicanos del 10 de mayo de 1917, que ha sufrido aproximadamente 250 reformas; López Guerra y Aguiar, op. cit., nota 4, p. 715.

24 Ortiz Ahlf, Loretta, Revista del Instituto de la Judicatura Federal, México, Instituto de la Judicatura Federal, núm. 8, 2001, pp. 235 y ss. 